\title{
THE INTEGRATION OF BLENDED LEARNING APPROACH IN MOROCCAN HIGHER EDUCATIONAL INSTITUTIONS: MOHAMMED I UNIVERSITY OUJDA AS A CASE STUDY
}

\author{
Assya Bouali \\ Dr., Mohammed First University, Morocco, assya.bouali@gmail.com
}

\begin{abstract}
This piece of research adds to the growing number of studies by investigating the blended-learning experience lived in Moroccan higher educational institutions namely that of University Mohammed the first. It aims to explore, describe, and assess the blended-learning experience adopted in a postgraduate degree called 'Engineering of Training and Educational Technology' EFTE. It then seeks to present the variety of modes of instruction adopted within this blended-learning training.
\end{abstract}

Keywords: Blended-Learning, Teaching, Learning, Instruction, Education, Technology.

\section{INTRODUCTION}

The development of technology has interfered in every sphere of the daily reality of people's lives, as it has even affected the educational process. While in today's world characterized essentially by the wireless Internet and open-free sources of information, technology has become increasingly integrated in our dailylife. Thus, the advancement of information communication technologies (ICT) has shaped the way we perceive knowledge building and provided new circumstances for more effective and efficient implementation of learning programs.

\section{REVIEW OF LITERATURE}

\subsection{Overview on Blended-Learning}

Indeed, ICT has interfered in a way that has had a huge influence on teaching practices. By means of innovations in the field of education, a shift in paradigm has globally taken place moving from a mere concentration on lecture-centered approaches to learner-centered instruction, where students are in the focus and educationists provide adequate instructional design that suits and supports these learning environments.

As a matter of fact, there are plethora of forms that are correlated to Online education such as distant education, hybrid, blended or mixed mode of learning, web-based, and web-enhanced. These are the main varieties of online education that have been notoriously characterized by technological interference.

Smith and Kurthen(2007) categorized today's distance learning into four concepts: web-enhanced, blended, hybrid learning and fully online. Loveless (2006), on the other hand, asserts that we live and work in 
interesting times during which the cultural and political contexts of education raise challenges to many practices and beliefs.

An increasing number of studies accentuate the effectiveness of blended-learning and its implementation in higher educational contexts. "The emerging technologies in higher education have fostered the interest in blended learning" (Chew, 2008: 344).

While the blended mode of learning has gained this global interest mainly due to the advantages it has provided including but not limited to cost effectiveness, learner-control, flexibility, feedback, access to authentic resources and personalization. Thorne (2003: p. 18) states that 'Blended learning could become one of the most significant developments of the 21 st century".

\subsubsection{Origins of the Term}

The term blended learning has first appeared in the business world particularly in connection with corporate training (Sharma and Barrett, 2007). It was then employed in higher education (MacDonalds, 2006), and lastly appeared in language teaching and learning. While the exact time of its emergence in English Language teaching remains difficult to define. However, it could be claimed that it has coincided with the publication of Sharma and Barrett's book Blended Learning in 2007. Furthermore, Claypole (2003: 169) assumed that Blended learning is nothing new and that it is indeed the logical development of prior tendencies involving the mixing of methods of teaching.

As a matter of fact, the length of use and ubiquity of the Internet has driven practitioners and educationalists to a completely new space, ambiguous for some and dangerous for others, where revisiting the way language instruction is delivered was a must and making more radical changes to fit and cope with the rapid development of information, Communication, technologies. Hence, the term blended has been used for decades without being consciously conceptualized and blended learning by no means signifies the introduction of a completely new theory of teaching and learning but it simply implies a mix of face-to-face and online instruction with activities mediated by technology.

What is now termed as blended learning does not necessarily rely on the simple use of technology. It does, as a point of fact, depend on the amount of work and the balance between what is done in class setting and what ought to be done online and outside of the class walls. Undoubtedly, the rapid technological advance is developing at a faster pace. This has radically affected the daily lives of people and the way they do things thus, the way they teach, learn and interact with each other. However, some of the things seem to remain constant, always the same, resisting the change especially when the focus is shifted towards second or foreign language acquisition. In this sense, Michael McCarthy (2016) asserts that:" Some things remain stubbornly (or perhaps reassuringly) constant: human beings struggle to learn foreign languages, to break the habits of a lifetime ingrained by their first language, to overcome the seemingly insurmountable obstacles of confronting new grammar and thousands of new words in the target language, along with new ways of pronouncing words and new challenges in communicating through the medium of the target language and its associated culture" (p.2). That is to say, technology can help produce effective teaching and learning practices if it is adopted for pedagogical reasons and for the benefits it might bring.

\subsubsection{Definitions of the Term}

In spite of the fact that blended learning has been presented and used for decades, there is still some sort of ambiguity in the definitions being produced for it. Some have already claimed that it is difficult to find a suitable, concrete definition for the term. Perhaps because it is the only piece of technological landscape that could marry both pedagogy and practice with the new innovations in teaching and learning. (Sharpe, Benfield, Roberts, and Francis ( 2006: 18) stated that despite the fact that blended learning has been in use for more than 20 years, its definition has been constantly changing during this period of time.

However, there have been times where blended learning was referred to as 'hybrid or mixed learning'. As a matter of fact, there are plethora of forms that are correlated to online education such as distant education, hybrid, blended or mixed mode of learning, web-based, and web-enhanced. These are the main varieties of online education that have been notoriously characterized by technological interference.

Smith and Kurthen(2007) categorized today's distance learning into four concepts: web-enhanced, blended, hybrid learning and fully online. In an attempt of differentiating between these concepts, Table 1 uses this percentage. 
IJAEDU- International E-Journal of Advances in Education, Vol. IV, Issue 10, April 2018

Table 1.Taxonomy of terms related to blended learning (Smith and Kurthen 2007, in Gruba and Hinkelman 2012: 4)

\begin{tabular}{|c|c|}
\hline Term & Definition \\
\hline Web-enhanced & $\begin{array}{c}\text { Subjects that make use of a minimal amount of online materials, such as } \\
\text { posting a syllabus and course announcements. }\end{array}$ \\
\hline Blended & $\begin{array}{c}\text { Subjects that utilize some significant online activities in otherwise face-to-face } \\
\text { learning, but less than } 45 \text { per cent. }\end{array}$ \\
\hline Hybrid & $\begin{array}{c}\text { Subjects in which online activities replace } 45 \_80 \text { per cent of face-to-face } \\
\text { class meetings. }\end{array}$ \\
\hline Fully online & $\begin{array}{c}\text { Subjects in which } 80 \text { per cent or more of learning materials are conducted } \\
\text { online. }\end{array}$ \\
\hline
\end{tabular}

Despite these differences being presented, it could be argued that in ELT contexts, these terms are basically used to convey the same meaning. Blended learning is referred to as any kind of combination between faceto-face or classroom instruction and online or computer-mediated environments.

If we define the term "blend" from an ordinary dictionary, we find a range of definitions that are introspected yet used to convey the same meaning. Macmillan dictionary defines it as "a combination of different tasks, styles, qualities etc. that produces an attractive or effective result". Whereas Cambridge English Dictionary gives the term a similar definition using "a mixture of different things or styles" "to blend is to mix or combine together". Nevertheless, Blended learning as an approach to teaching and learning implies a different yet more practical definition. Banados, (2006: 534) defines it as follows: "a combination of technology and classroom instruction in a flexible approach to learning that recognizes the benefits of delivering the same training and assessment online but also uses other modes to make up a complete training programme which can improve learning outcomes and/or save costs".

Oliver and Trigwell (2005: 17) defined it as 'The integrated combination of traditional learning with web based online approaches". Traditional learning here implies face-to-face or classroom teaching. And the online part usually involves a (VLE) Virtual Learning Environment or an (LMS) Learning Management System.

Interestingly, the definitions provided by ELT practitioners seem to be succinct and of clear meaning. Neumeier (2005: 164) defines blended learning as 'a combination of face-to-face (F-t-F) and computer assisted learning (CALL) in a single teaching and learning environment". These latter have been described as 'context specific' by Levy and Stockwell (2006: 234).

However, the widely recognized and praised authors in the topic, Dudeney and Hockly (2007) described blended learning as "a mixture of online and face-to-face course delivery'. Sharma and Barrett (2007) go on a deeper definition 'Blended learning refers to a language course which combines a face-to-face (F2F) classroom component with an appropriate use of technology.

\section{PURPOSE OF THE STUDY}

Nowadays, many universities around the globe have attempted to respond to the new changes related to digital culture. Among these, we can state the case of Mohammed I University, but most precisely, the faculty of Letters and Humanities in Oujda, Morocco.

This study is an empirical study that aims at describing and evaluating the effectiveness of blended learning mode of instruction in a context known by the adoption of traditional mode of delivery. A two years Master's degree training has been selected for experimentation. It is the only experience that integrates the blended learning mode of instruction at the targeted university.

To accomplish this purpose, the research questions for the study were conducted as follow: (1) what are the cornerstones and the bedrocks on the basis of which this experience is held? (2) What is the main purpose behind the adoption of blended learning in postgraduate context? (3) Do the coordinators redesign the curriculum so as to meet the requirements of blended learning mode of learning? Is there any significant difference related to the practices of instructors and teachers? 


\section{BACKGROUND INFORMATION ON THE TRAINING}

It is a master's degree program called IFTE (Ingénierie de Formation et Technologies Educatives) Engineering of training and Educational Technologies. A training provides $60 \%$ of modules online and $40 \%$ in classroom setting. The main focus is built upon learners' acquisition of key skills such as observation, analysis, leadership and synthesis.

This training goes beyond the traditional conception of teaching and aims mainly at endowing learners with competences related to the design of innovative training devices and prepares them for leading roles such as: Designers and directors of multimedia products, managers of publicized training devices as well as tutors in both distant and face-to-face instruction setting.

Furthermore, among the competences to be acquired and developed during the training, the following could be stated:

$\checkmark$ Analysis and assessment of the training devices.

$\checkmark$ Designing and administrating blended learning and online devices.

$\checkmark$ Boosting the capacities of research and inquiring mind in the field of educational technology.

\section{DESIGN OF THE STUDY}

Permission was provided in order to have access to the adapted online platform and to do some observation classes. Within the platform, a selection process was made in order to choose a variety of modules that are different in terms of work requirements and teaching practices. The idea behind this was to give a clear and thorough overview on different modules ranging from "quality management", "entrepreneurial projects" and "Distant learning and tutoring".

\subsubsection{Treatment}

This case study training is founded upon Dick and Carey's instructional Design Model which is based on a systematic approach to designing instruction. This model attempts to define each step in details for the instructors. Indeed, the same scholars (2005) have asserted that learning is a systematic process in which every component including instructors, learners, materials, instructional activities, learning and performance environments are crucial to successful learning outcomes.

This model is adapted in the training program since it is characterized by an iterative process that identifies instructional goals first and then end up with a summative evaluation. As a matter of fact, learners are supposed to take a pretest and posttest at the beginning and at the end of the training. To iterate, the pretest is held as to diagnose learners' prerequisites and pre-acquired and to see whether these learners have the potential and competences necessary that will help them continue the training successfully. The formative assessment is achieved through a variety of activities either individually or in collaboration, where the instructor gives feedback on student's performance and encourages them in the process.

The posttest, on the other hand, is done at the end of the training as a sort of summative assessment through which instructors analyze learner's achievements and outcomes.

\subsubsection{Analysis}

This blended learning experience is divided into two modes of instruction, some of them are held online and others are in the classroom settings. The online instruction is supported by a platform called "CLAROLINE". However, the instruction itself varies from one instructor to another and from one module to another. Some modules are characterized by so much online learning instruction with the use of diverse tools of learning and interaction ranging from synchronous online formats such as: virtual classrooms, web seminars, Broadcasts and instant messaging. Among the tools of interaction that are so much of use, the following can be stated: Chat-rooms, discussion sessions, forums, wikis, Google docs for collaborative work, emails and hangouts.

An example of this mode of instruction was highly present in the module of "Quality Management".

\section{RESULTS AND DISCUSSION}

In the figures $1 \& 2$, noticeable is the amount of online interaction and the active use of tools provided by the platform either from the instructor or the learners. Emails and web announcements are used as a means of learner-teacher interaction. 


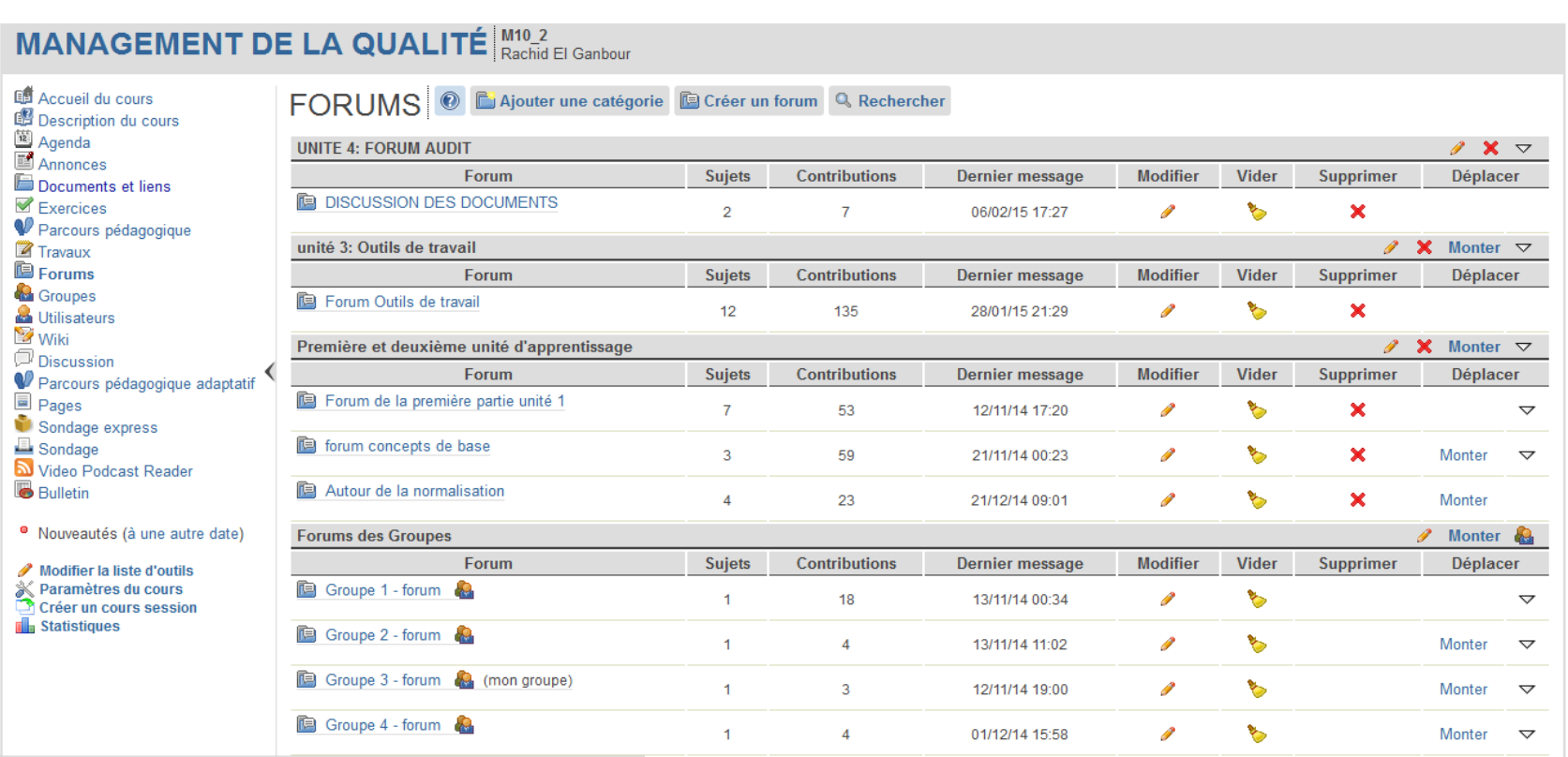

Figure 1. A screenshot of an example of rich forum discussion and debates

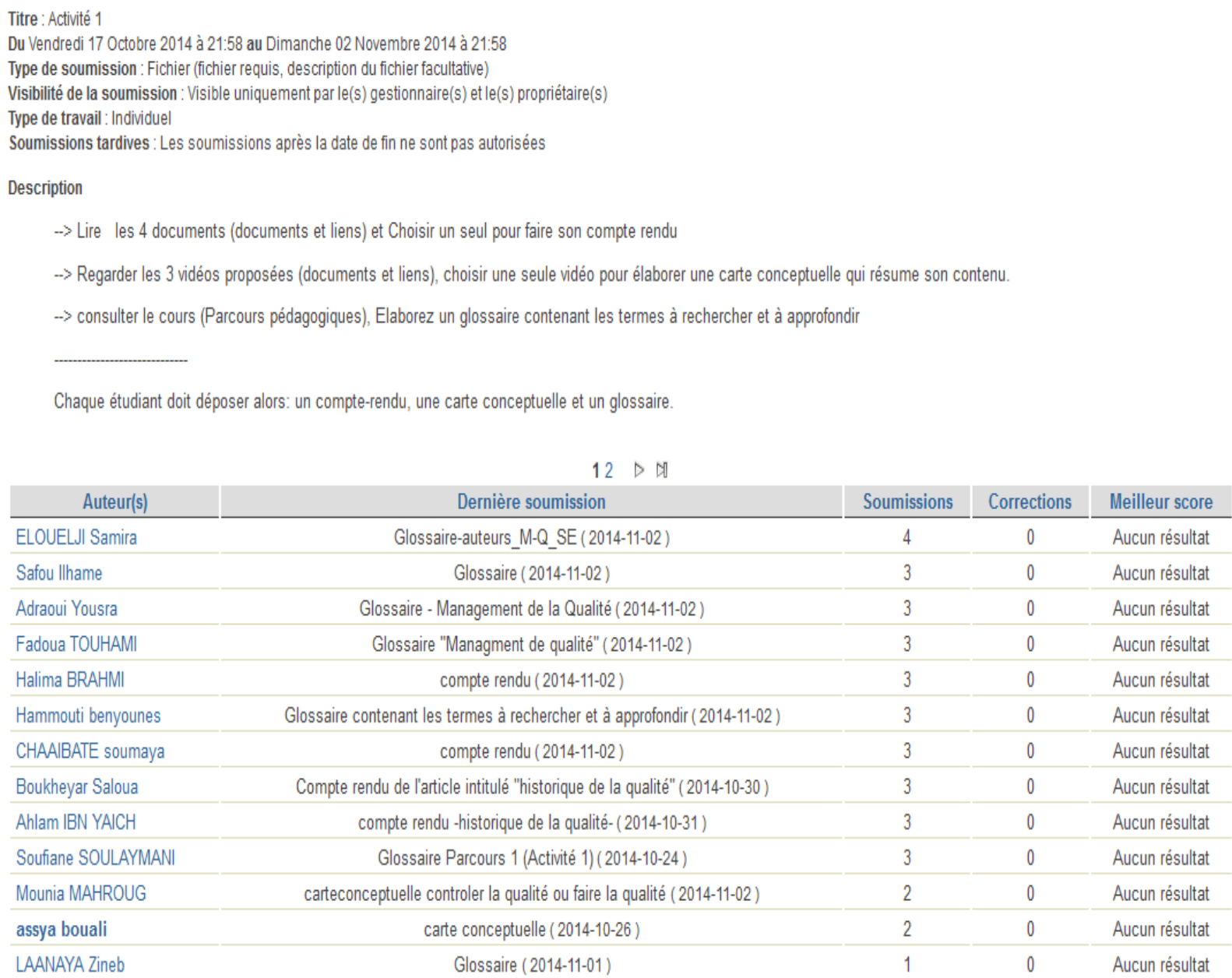

Figure 2.A screenshot of a variety of activities done by learners.

Nevertheless, despite the fact that the training is based on blended learning approach, there are still instructors that do not make full use of online instruction. Their usage is limited to simple access to authentic resources and emails. In figure 3\&4, an example of a course called "Entrepreneurial projects" is depicted. 


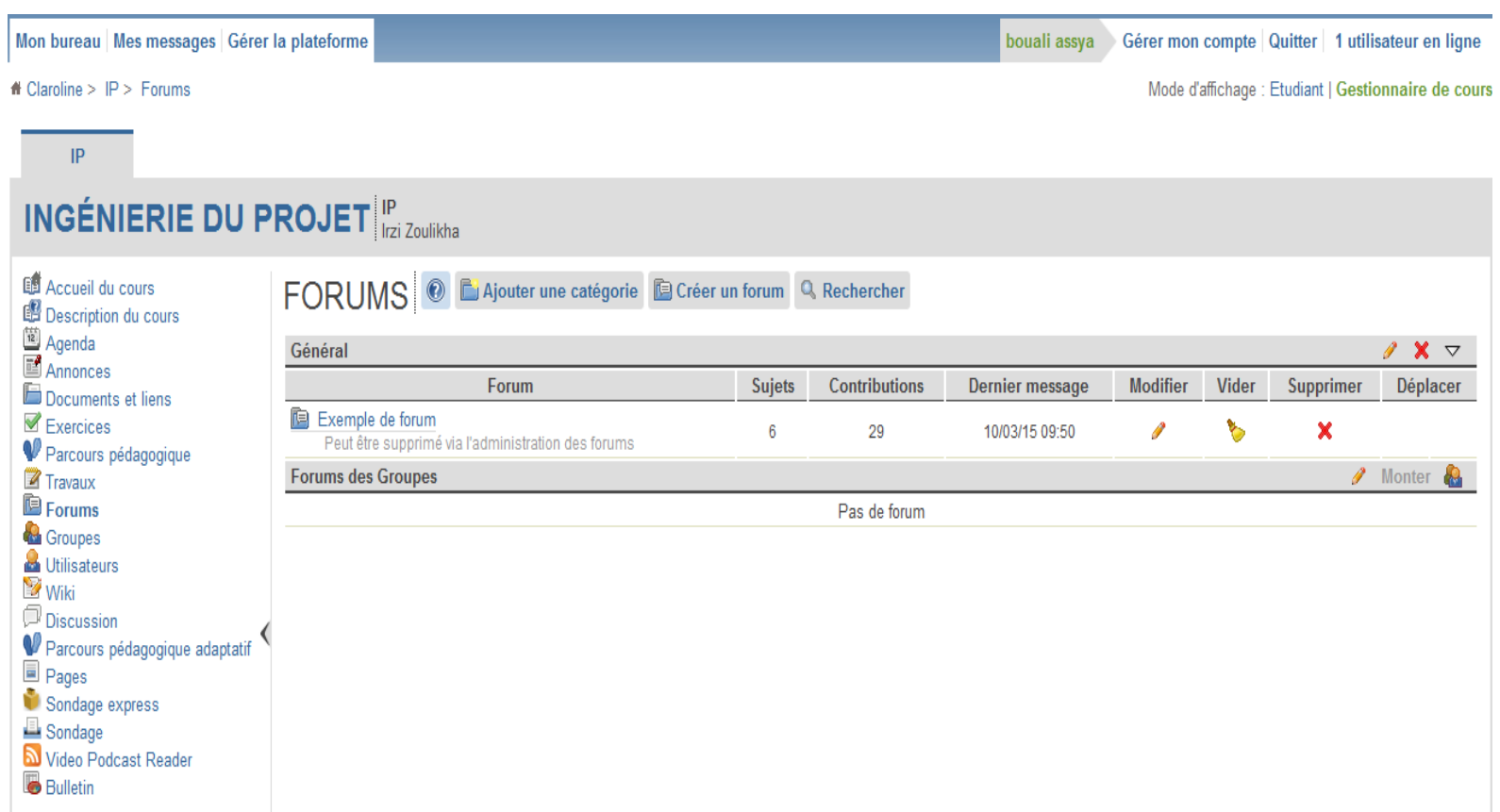

Figure 3.A screenshot of a screen capture of the forum.

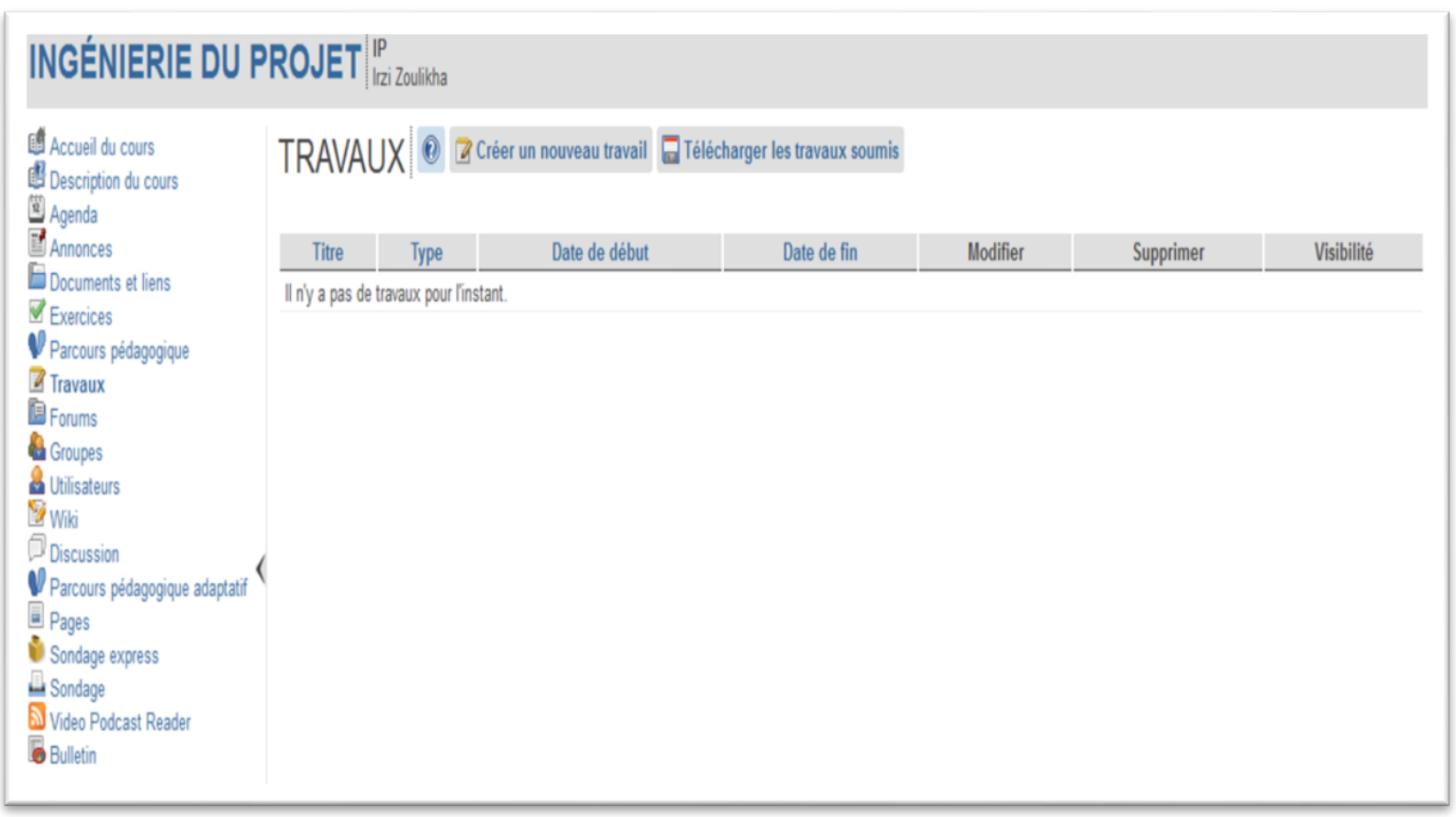

Figure 4.A screenshot of the online workspace.

As seen in figure $3 \& 4$, the spaces of interaction and activities are fully empty. This instructor gives the courses traditionally. To illustrate, it is an instructor-led classroom based on lecture courses that are supported by PowerPoint presentations, books and lecture notes.

Moreover, this course includes a weekly Q\&A session that is led by the instructor with the aim of providing learners with plenty of collaboration and teamwork opportunities.

The third and last module that was selected for the experimentation is called "Distant learning and tutoring". It is formulated in different formats within the blended learning approach, which is referred to as "Flippedclassrooms". This module, indeed, is a concrete and tangible example of a creative mode of learning, whereby authentic resources are provided online and learners come to class not to be transmitted the knowledge but most importantly to discuss, collaborate and interact with their peers. The following figures depict more in depth this mode of instruction: 


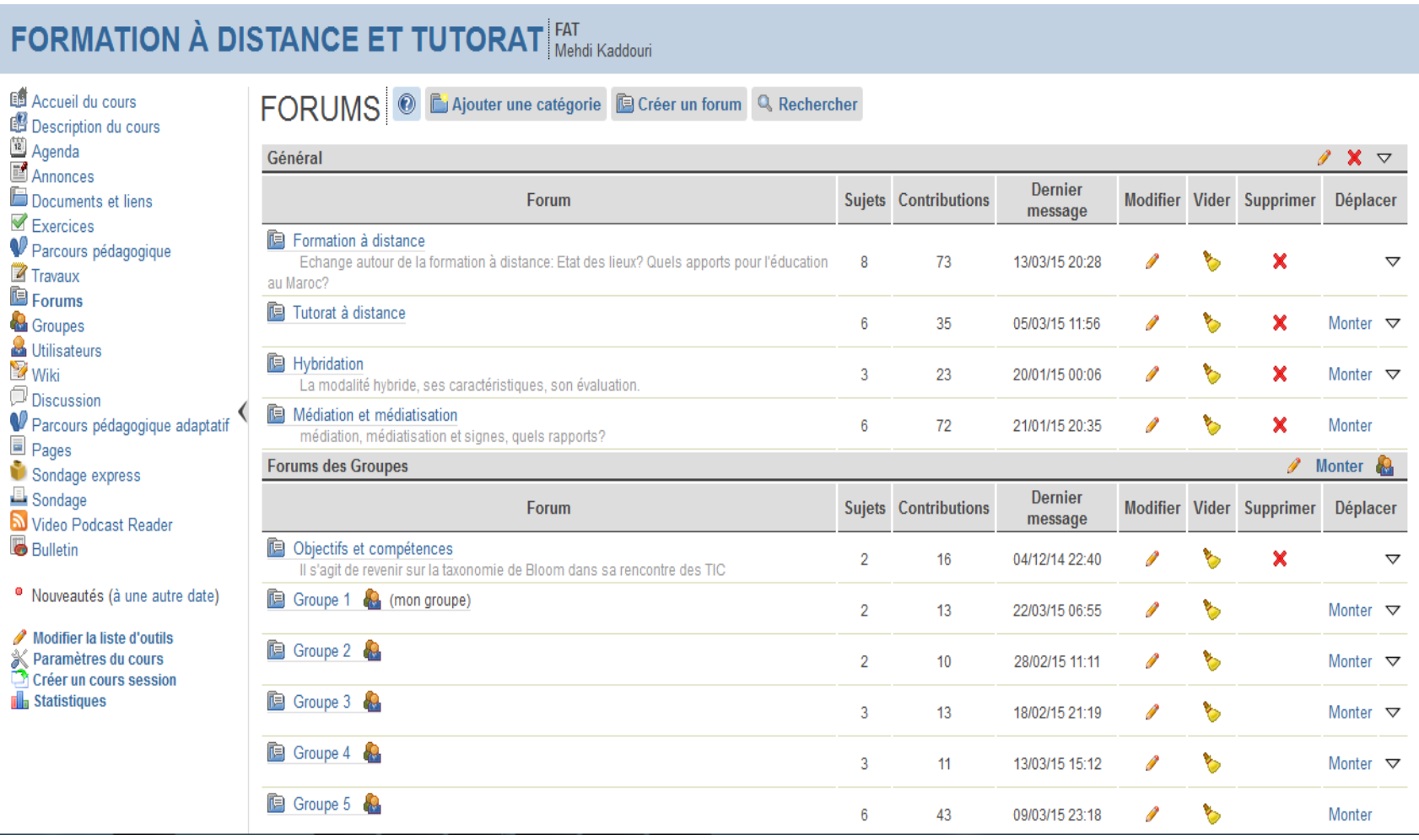

Figure 5.A screenshot of forum of the module "Distant learning and tutoring".

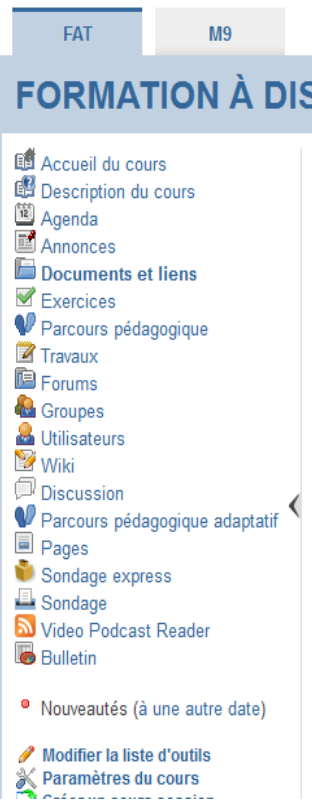

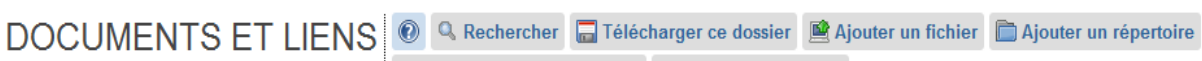

$$
\begin{aligned}
& \Leftrightarrow \text { Ajouter un lien hypertexte } \text { : Créer un document }
\end{aligned}
$$

\begin{tabular}{|c|c|c|c|c|c|c|}
\hline \multicolumn{7}{|c|}{ B Liste des fichiers | } \\
\hline Nom & Taille & Date de dernière modification & Modifier & Supprimer & Déplacer & Visibilité \\
\hline 回 Tutorat_a_distance & & & $\theta$ & $x$ & 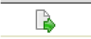 & $\widetilde{\Sigma}$ \\
\hline \multicolumn{7}{|l|}{ TAD } \\
\hline ఖon 6_niveaux_de_la_taxonomie_de_bloom.pdf & $47.61 \mathrm{Ko}$ & 13/10/2014 & $\theta$ & $x$ & 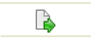 & $\tilde{\Sigma}$ \\
\hline DIS_011_0019.pdf & $230.34 \mathrm{Ko}$ & 13/10/2014 & 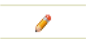 & $x$ & 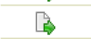 & $\overleftarrow{\tau}$ \\
\hline 㔚 DIS_011_0047.pdf & $75 \mathrm{Ko}$ & $13 / 10 / 2014$ & $\theta$ & $x$ & 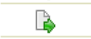 & 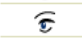 \\
\hline DIS_011_0061.pdf & $95.3 \mathrm{Ko}$ & 13/10/2014 & 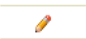 & $x$ & 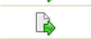 & $\overleftarrow{\tau}$ \\
\hline 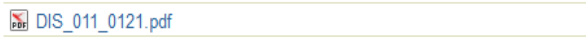 & $145.91 \mathrm{Ko}$ & $13 / 10 / 2014$ & $\theta$ & $x$ & 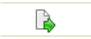 & $\tilde{\tau}$ \\
\hline 圖 Emploi_du_tempsDTE14-S3Vf.doc & $109.5 \mathrm{Ko}$ & $11 / 10 / 2014$ & $\theta$ & $x$ & 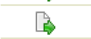 & 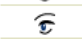 \\
\hline [R La_FAD,_cet_enseignement_dont_nous_ne_sommes_pas_les_heros.url & 324 Octets & $15 / 01 / 2015$ & $\theta$ & $x$ & $\Leftrightarrow$ & $\tilde{\Sigma}$ \\
\hline \multicolumn{7}{|l|}{ Réflexions et programme de recherche pour le tutorat en FAD } \\
\hline 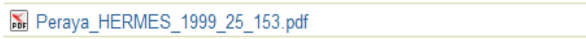 & $823 \mathrm{Ko}$ & 10/12/2014 & $\theta$ & $x$ & $\Rightarrow$ & $\tilde{\Sigma}$ \\
\hline [R Peut-on_parler_du_-metier__de_tuteur_a_distance_-url & 324 Octets & $15 / 01 / 2015$ & a & $x$ & 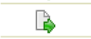 & 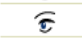 \\
\hline \multicolumn{7}{|l|}{ Ilham Safou } \\
\hline 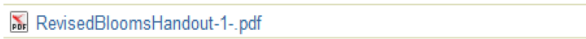 & $1.64 \mathrm{Mo}$ & $12 / 10 / 2014$ & $\theta$ & $x$ & $\$$ & $\tilde{\Sigma}$ \\
\hline
\end{tabular}

Figure 6. A screenshot of resources provided online.

A shift in paradigm related to instructors' roles as well as their perception of learners has been noticed. The instructor's role is not the transmission of knowledge. The instructor is, therefore, here to guide, to orientate discussion, and to provide answers to ambiguous questions being raised by learners.

Within this mode of instruction, learners are no more perceived as "tabula rasa" to be filled with knowledge or hailed as passive consumers of knowledge. Learners are henceforth considered as mindful individuals who are capable of working independently, using their creative and critical thinking skills.

\section{CONCLUSION}

It can be inferred that this blended learning experience includes different formats of instruction including online instruction, hybrid or blended instruction and traditional face to face instruction. So many whys and 
wherefores stand behind this diversity of instruction modes mainly teacher's lack of digital teaching experience, defect of university's infrastructure, and the unwillingness expressed among some instructors to accept the integration of technology in the educational arena.

In future conducted research, the emphasis will be put on learner's attitudes towards the use of blended learning mode of delivery. Also, a comparative study will be held between the blended learning and traditional mode of instruction as to measure the effectiveness of learning outcomes.

\section{REFERENCE LIST}

Ben-Daya, M., Darwis, M. and Ertogral, K. (2008). The joint economic lot sizing problem: Review and extensions. European Journal of Operational Research, vol. 185.

Goyal, S. K. (1977).An integrated inventory model for a single supplier-single customer problem.International Journal of Production Research, vol.15.

AECT (1972) 'The field of Educational Technology: A Statement of Definition', Audiovisual. Instruction, 17,36-43.

Ala-Mutka., Punie, Y., \&Redecker, C. ICT for Learning, Innovation and Creativity.IPTS.Seville, 2008.

ALLAN, B. (2007) Blended Learning Tools for Teaching and Training. London: FacetPublishing.

ANDERSON, G. (2004) Fundamentals of educational Research (2nd Edition). London:RoutlegeFalmer.

ARBAUGH, J., B. (2004) 'Learning to Learn Online: A Study of Perceptual Changes betweenMultiple Online Course Experiences', Internet and Higher Education, 7, 169-182.

Attwell, G. (2007) (a). Personal Learning Environments- The Future of e-learning? E-LearningPapers, 2(1).

Attwell, G. (ed.), (2007) (b). Searching, Lurking and the Zone of Proximal Development,e-learning in Small and Medium Enterprises in Europe. Vienna: Navreme.

Attwell, Graham (2007). The Personal Learning Environments - the future of eLearning? E-Learning Papers, vol. 2 no. 1.ISSN 1887-1542.

Ayala, J. (2009). Blended learning as a new approach to social education. Journal of Social Work Education, 45(2), 277-288. Retrieved from Academic Search Complete database.

BATES A., W. and POOLE, G. (2003) Effective Teaching with Technology in Higher Education.CA: John Wiley \& Son.

Becker, R., \&Jokivirta, L. (2007). Online Learning in Universities: Selected Data from the 2006Observatory Survey. London: Observatory on Borderless Higher Higher Education.

BEREDAY, G., F. (1965) Comparative Method in Education. New York: Holt, Rinehart andWinston.

BERSIN, J. (2004) The Blended Learning Book: Best Practices, Proven Methodologies, andLessons Learned. San Francisco: Pfeiffer.

BIELAWSKI, L. and METCALF, D. (2003) Blended eLearning: Integrating Knowledge,Performance, Support and Online Learning. MA: HRD Press Inc.

BLIUC, A., M., GOODYEAR, P. and ELLIS, R., A. (2007) 'Research Focus and Methodological Choices in Studies into Students' Experiences of Blended Learning in Higher Education', Internet and Higher Education, 10, 231-244.

BONK, C., J. and GRAHAM, C., R. (Eds.) (2006) The Handbook of Blended Learning: GlobalPerspectives, Local Designs, San Francisco. CA: Pfeiffer Publishing.

Brown, J. S., \& Adler, R. P . (2008). Minds on fire: Open education, the long tail, and Learning2.0 Educause Review, 43, 1.

CHAN, J., K., Y AND LAW, K., C., K. (2008) 'Structured Blended Learning Implementation foran Open Learning Environment', In LEUNG H., LI, F., LAU, R. and LI, Q. (Eds) Advances inWeb Based Learning, Springer: Lecture Notes in Computer Science, 630-640.

CHEW, E. (2008b) Book Review for Barbara Allan: Blended Learning Tools for teaching andtraining, Journal 
of Educational Technology and Society, 11(2) 344-347.

Coffield, F . (2008). Just suppose teaching and learning became the first priority. Learning andSkills Network.

CORTAZZI, M. and HALL, B. (1999) 'Vygotsky and Learning', Education Libraries Journal,42(3), 17-21.

CRESWELL, J., W. (2007) Qualitative Inquiry Research Design: Choosing Among FiveApproaches (2nd Edition). London: Sage Publications.

Daele, Amaury, \&Lusalusa, Simon.(2003). Les apprentissagesvécus par les étudiants. InCharlier, Bernadette \&Peraya, Daniel, Technologie et innovation en pédagogie :dispositifsinnovants de formation pour l'enseignementsupérieur, 164-176.

DALSGAARD, C. and GODSK, M. (2007) 'Transforming Traditional Lectures intoProblem-based Blended Learning: Challenge and Experiences', Routledge: Open learning, 22(1),29-42.

Davis, H. C., \& Fill, K. (2007). Embedding blended learning in a university's teachingculture: Experiences and reflections. British Journal of Educational Technology, 38(5), 817-828.

Davis, N., Roblyer, M. D. P., Charania, A., Ferdig, R., Harms, C., Compton, L. et al. (2007).Illustrating the virtual ?in Virtual Schooling: Challenges and Strategies for creating real tools toprepare virtual teachers. Internet and Higher Education, 10, 27-39.

Dick, W., Carey, L., \& Carey, J. O. (2005). The systematic Design of instruction. Boston: Allyn\& Bacon.

Doolittle, P. E., \& Camp, W. G. (1999). Constructivism: the career and technical education Perspective. Journal of Vocational and Technical Education, Volume 16, Number 1.

Downes, S. (2005). E-learning 2.0,.eLearn Magazine.

FINN, J., D (1972) 'The Emerging Technology of Education', In McBRATH, R., J. (Ed.), Extending Education Through Technology. Selected Writing by James D. Finn, Washington:AECT.

LOVELESS, A., M. (2006) 'Where do You Stand to Get a Good View of Pedagogy?' Journal of Technology and Teacher Education, 8(4), 337-349.

Russell, T. (1999). The no significant difference phenomenon. Chapel Hill: North Carolina State University.

Smith, G. G., \&Kurthen, H. (2007).Front-stage and back-stage in hybrid e-learning face-to-face courses. International Journal on E-Learning, 6(3), 455-474.

THRONE, K. (2003) Blended Learning: How to Integrate Online \& Traditional Learning. London: Kogan Page.

Attwell, G. (2010). (b). The Future of Learning Environments.

http://www.pontydysgu.org/2010/06/the-future-of-learning-environments-short-version/

Attwell, Graham (2007). The Personal Learning Environments - the future of eLearning?

http://www.informelles-lernen.de/fileadmin/dateien/Informelles_Lernen/Buecher_Dokumente/Attwell_2007ple.pdf

ARABASZ, P. and BAKER, M., B. (2003) Evolving Campus Support Models for E-LearningCourses, Center for Applied Research (ECAR) Respondent Summary. Retrieved 25 January 2008from: http://www.educause.edu

BBC (2004) Problems at e-learning University. Retrieved 11 April 2008 from:http://news.bbc.co.uk/1/hi/education/3494048.stm

CARMAN, J., M. (2002) Blended Learning Design: Five Key Ingredients, Knowledgenet.Retrieved 11 December 2007 from:

http://www.knowledgenet.com/pdf/Blended\%20Learning\%20Design_1028.PDF

CELT (2006) Centre of Excellent for Learning and Teaching, University of Glamorgan.Retrieved 22 April 2007 from: http://celt.glam.ac.uk 